\title{
Resistance to Cotrimoxazole and Other Antimicrobials among Isolates from HIV/AIDS and Non-HIV/AIDS Patients at Bugando Medical Centre, Mwanza, Tanzania
}

\author{
Karol J. Marwa, ${ }^{1}$ Martha F. Mushi, ${ }^{2}$ Eveline Konje, ${ }^{3}$ Paul E. Alele, ${ }^{4}$ \\ Jeremiah Kidola, ${ }^{5}$ and Mariam M. Mirambo ${ }^{2}$ \\ ${ }^{1}$ Department of Clinical Pharmacology, Weill Bugando School of Medicine, P.O. Box 1464, Mwanza, Tanzania \\ ${ }^{2}$ Microbiology and Immunology Department, Weill Bugando School of Medicine, P.O. Box 1464, Mwanza, Tanzania \\ ${ }^{3}$ Department of Community Medicine, School of Public Health, Catholic University of Health and Allied Sciences, \\ P.O. Box 1464, Mwanza, Tanzania \\ ${ }^{4}$ Department of Pharmacology, Mbarara University of Science and Technology, P.O. Box 1410, Mbarara, Uganda \\ ${ }^{5}$ National Institute for Medical Research, P.O. Box 1462, Mwanza, Tanzania \\ Correspondence should be addressed to Martha F. Mushi; marthamushi@yahoo.com
}

Received 11 September 2014; Revised 20 January 2015; Accepted 31 January 2015

Academic Editor: Otoniel Martinez-Maza

Copyright (C) 2015 Karol J. Marwa et al. This is an open access article distributed under the Creative Commons Attribution License, which permits unrestricted use, distribution, and reproduction in any medium, provided the original work is properly cited.

Bacterial resistance has increased in the AIDS era and is attributed to the widespread use of cotrimoxazole prophylaxis against opportunistic infections in HIV/AIDS patients. In Tanzania, cotrimoxazole prophylaxis has been used for more than ten years. Little is known, however, about its impact on the spread of antibiotic resistance in HIV positive patients. This cross-sectional study was done to compare magnitude of bacterial resistance to cotrimoxazole and other antimicrobials among isolates from HIV infected patients on cotrimoxazole prophylaxis and those not on prophylaxis and non-HIV patients attending Bugando Medical Centre (BMC). Susceptibility testing on obtained urine and swab specimens followed Clinical Laboratory Standard Institute, 2010, Guidelines. Of 945 samples collected, 155 had positive bacterial growth after 24 hours of incubation. Of the positive samples (72), 46.4\% were from HIV positive patients. The common isolates were E. coli 41.3\% (64/155), Klebsiella pneumoniae 17.5\% (27/155), and Staphylococcus aureus 16.1\% (25/155). Overall, bacterial resistance to cotrimoxazole was 118 (76.1\%); among isolates from HIV patients bacterial resistance was 54 (75\%), and for isolates from HIV patients on prophylaxis bacterial resistance was 36 (81.3\%). HIV seropositivity and cotrimoxazole prophylaxis are not associated with antibiotic resistance observed in bacteria infecting patients attending BMC, Mwanza, Tanzania.

\section{Background}

Multidrug resistance (MDR) bacteria like extended spectrum beta lactamase (ESBL) producers and methicillin-resistant Staphylococcus aureus (MRSA) are a major public health concern the world is facing $[1,2]$. In developing countries where treatment options are limited MDR has led to increased morbidity and mortality [3]. Treatment of common bacterial infections like acute respiratory tract infections, urinary tract infections, wound infections, meningitis, and blood stream infections are very difficult when associated with MDR bacteria [4]. The problem is complex and is influenced by many interconnected factors such as poverty, self-medication, and misdiagnosis [3]. Chronic use of a specific antibiotic has been documented as the commonest factor that influences antibiotic resistance. This is due to constant exposure of bacteria to antibiotic pressure [2].

Cotrimoxazole has been used as a prophylactic agent against opportunistic infections in HIV/AIDS patients worldwide. In Tanzania, cotrimoxazole has been used as a prophylactic agent for over 10 years now and is used in all HIV and AIDS patients, starting with WHO stage 3, all adult persons with symptomatic HIV disease including HIV symptomatic pregnant women after the first trimester and 
before 37 weeks of pregnancy, and all children born of HIV positive women [5]. For non-HIV patients, in Tanzania, cotrimoxazole is used in diarrheal diseases [6]. Besides records of resistance reported before initiation of cotrimoxazole as a prophylactic agent, the chronic use of this drug among AIDS patients is expected to increase resistance due to selective pressure [7]. Previous studies have demonstrated a relationship between antibiotic consumption and the incidence of antimicrobial resistance in various bacterial infections [8-10].

A study undertaken in Soweto, South Africa, reported high resistance of $K$. pneumoniae and $S$. aureus to cotrimoxazole among isolates from HIV infected patients [11], with no data for HIV negative patients. The present study was carried out to determine the magnitude of bacterial resistance to cotrimoxazole and other antimicrobials among isolates from HIV infected patients on cotrimoxazole prophylaxis and those not on prophylaxes and non-HIV patients attending Bugando Medical Centre (BMC) in Mwanza, Tanzania.

\section{Materials and Methods}

This was a cross-sectional study conducted at microbiology laboratory of BMC from January to October 2012. This laboratory receives an average of 50 request forms for microbiological investigation of urine and pus samples per week. $\mathrm{BMC}$ is a consultant and teaching referral hospital for the Lake and Western zones of the United Republic of Tanzania. A systematic random sampling method was used whereby the laboratory investigation forms were assigned numbers daily; then all 1st, 5th, and 9th numbers were picked. Patients who were represented by these numbers were included in the study giving a total of 945 patients.

2.1. Laboratory Procedures. Urine and pus swab specimens were collected from enrolled participants. Specimens were processed as per standard operative procedures of the BMC laboratory adopted from the District Laboratory Practice manual in tropical countries [12]. Identification of bacteria was made by conventional physiological and biochemical methods $[13,14]$.

Antimicrobial susceptibility tests were done using the disk diffusion method (Kirby-Bauer's) according to Clinical and Laboratory Standards Institute (CLSI) [13] and WHO manual [14]. The antimicrobial discs tested include sulfamethoxazole/trimethoprim $(1.25 / 23.75 \mu \mathrm{g})$, ampicillin $(10 \mu \mathrm{g})$, erythromycin ( $15 \mathrm{mcg})$, ciprofloxacin $(5 \mu \mathrm{g})$, ceftriaxone $(30 \mu \mathrm{g})$, tetracycline $(30 \mu \mathrm{g})$, and amoxycillin/clavulanic acid $(20 \mu \mathrm{g})$. ESBL production was detected by using disc approximation method [15]. All these disks were obtained from Oxoid Hampshire (UK). Quality control was done using Staphylococcus aureus ATCC 25923 for gram positive bacteria and Escherichia coli ATCC 25922 for gram negative bacteria.

The results for the antimicrobial susceptibility test strain/ bacteria (while checking that results of the quality control strain are within acceptable control range) were interpreted as susceptible $(S)$ or resistant $(R)$ by comparing the results to the CLSI 2010 standard zone diameter [13].
Patients whose HIV status was not known were counselled by a trained nurse from a care and treatment centre (CTC) and then each patient was requested to fill a consent form. HIV testing was done as per Tanzania National Algorithms [16].

Ethical Issues. The ethical clearance for conducting this study was obtained from Faculty of Medicine Research and Ethics Committee and the Institutional Review Board of Mbarara University of Science and Technology (MUST) and Joint CUHAS/BMC Research Ethical Committee (CREC). The patients were informed about study protocol and were requested to fill and sign an informed consent form.

\section{Data Entry and Analysis}

Data was entered on EXCEL (2007) data sheet and transferred to STATA 8 (Statistical Corporation, College Station, TX, US) for statistical analysis. Descriptive statistics for sociodemographic characteristics were obtained with respect to data type. Chi-square and Fisher's exact tests were performed for determining association between categorical variables where appropriate. Binary logistics regression was performed; odds ratios (OR) and 95\% confidence intervals (95\% CI) were reported as a measure of effect. $P$ value of $\leq 0.005$ was considered as statistically significant.

\section{Results}

4.1. Demographic Data of the Study Participants. Of 945 patients' samples collected, 155 had significant bacteria growth and were analyzed. For analyzed samples (100) $64.5 \%$ were females. HIV positive patients were (72) $46.4 \%$ (Figure 1). Of HIV positive patients (44) $61 \%$ were on cotrimoxazole prophylaxis. Most of those who were not on cotrimoxazole prophylaxis were on WHO clinical stage 1, whereas most of those who were on cotrimoxazole prophylaxis were on stage 2 , stage 3 , or stage 4 (Table 1 ). Among HIV infected patients who were on cotrimoxazole prophylaxis, (31) $70.5 \%$ had CD4 count less than 350 whereas all of those not on prophylaxis had CD4 count greater than 350 (Table 1).

Majority of HIV patients on cotrimoxazole prophylaxis were on antiretroviral therapy (ART) (97.7\%) while 67.9\% of those not on cotrimoxazole prophylaxes were on ART (Table 1).

4.2. Bacteria Isolated. The study isolated both gram positive and negative bacteria dominated by E. coli $41.3 \%$ (64/155), Klebsiella pneumoniae 17.5\% (27/155), and Staphylococcus aureus $16.1 \%$ (25/155) (Figure 2).

In this study E. coli was mostly isolated from samples from $\mathrm{HIV}$ infected patients; samples from HIV negative patients showed a much higher percentage of other bacterial isolates like $S$. aureus. This study reveals higher resistance of $E$. coli to amoxicillin-clavulanic acid (43.6\%), ampicillin (82.5\%), tetracycline (78\%), and cotrimoxazole (84.4\%) (Table 2$)$.

Of 155 samples with significant bacteria growth 72 (46.5\%) were from HIV positive people. Bacteria resistance to 
TABLE 1: Background characteristics of 155 patients as categorized by HIV status.

\begin{tabular}{|c|c|c|c|}
\hline \multirow{2}{*}{ Characteristics } & \multirow{2}{*}{ Total $(n)$} & \multicolumn{2}{|c|}{ HIV status } \\
\hline & & Negative & Positive \\
\hline Sex & 155 & & \\
\hline Male & & $26(47.3 \%)$ & $29(52.7 \%)$ \\
\hline Female & & $57(57.0 \%)$ & $43(43.0 \%)$ \\
\hline Sample & 155 & & \\
\hline Urine & & $9(15.2 \%)$ & $50(84.8 \%)$ \\
\hline Pus swab & & $74(77.1 \%)$ & $22(22.9 \%)$ \\
\hline Gram stain & 155 & & \\
\hline Negative & & $66(51.2 \%)$ & $63(48.8 \%)$ \\
\hline Positive & & $17(65.4 \%)$ & $9(34.6 \%)$ \\
\hline Admission status & 155 & & \\
\hline Outpatients & & $6(11.3 \%)$ & $47(88.7 \%)$ \\
\hline In patients & & $77(75.5 \%)$ & $25(24.5 \%)$ \\
\hline WHO clinical stage & 72 & & \\
\hline 1 & & NA & $23(32 \%)$ \\
\hline 2 & & NA & $21(29 \%)$ \\
\hline 3 & & NA & $18(25 \%)$ \\
\hline 4 & & NA & $10(14 \%)$ \\
\hline CD4 count & 72 & & \\
\hline$<350$ & & NA & $41(57 \%)$ \\
\hline$>350$ & & NA & $31(43 \%)$ \\
\hline Cotrimoxazole prophylaxis & 72 & & \\
\hline Not on prophylaxis & & NA & $28(39 \%)$ \\
\hline On prophylaxis & & NA & $44(61 \%)$ \\
\hline \multicolumn{4}{|l|}{ Antiretroviral therapy } \\
\hline Taking ART & 62 & NA & $62(83.3 \%)$ \\
\hline Not taking & 10 & NA & $10(16.7 \%)$ \\
\hline
\end{tabular}

$\mathrm{NA}=$ not applied.

cotrimoxazole on isolates from HIV infected patients was 54 (75\%) and on those from HIV negative patients was 64 (77\%) $(P=0.1)$. Similar results were observed with ampicillin, tetracycline, ceftriaxone, and ciprofloxacin (Table 3 ).

Of 72 isolates from HIV positive patients, 44 (61.1\%) were from patients on cotrimoxazole prophylaxis. Data on susceptibility patterns of these bacteria are presented on Table 4 .

\subsection{Extended Spectrum Beta Lactamase Production. Of 155} bacteria isolates in this study $36(23.2 \%)$ were ESBL producers. For isolates from HIV positive patients $23.6 \%$ (17/72) were ESBL producers. This study also found 44 isolates from HIV patients who were on cotrimoxazole prophylaxis, and, of them, 12 (27.3\%) were ESBL producers (Table 5).

The study also noted that cotrimoxazole, amoxicillinclavulanic acid, and ciprofloxacin resistance in bacteria can highly predict ESBL production. It was also found that being HIV positive and usage of cotrimoxazole prophylaxis do not predict ESBL production (Table 2). Resistance to cotrimoxazole and ciprofloxacin among ESBL producing

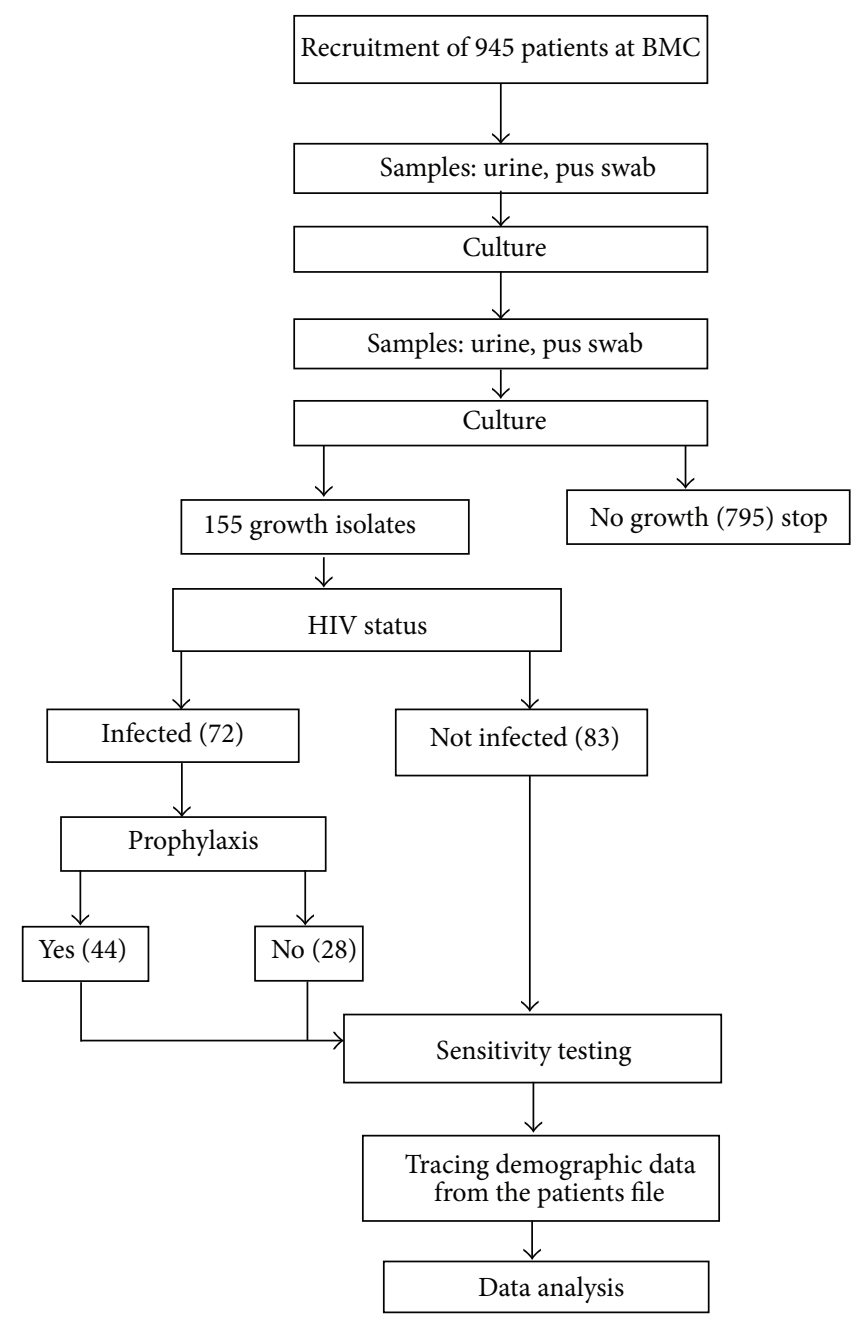

FIGURE 1: Study flow chart.

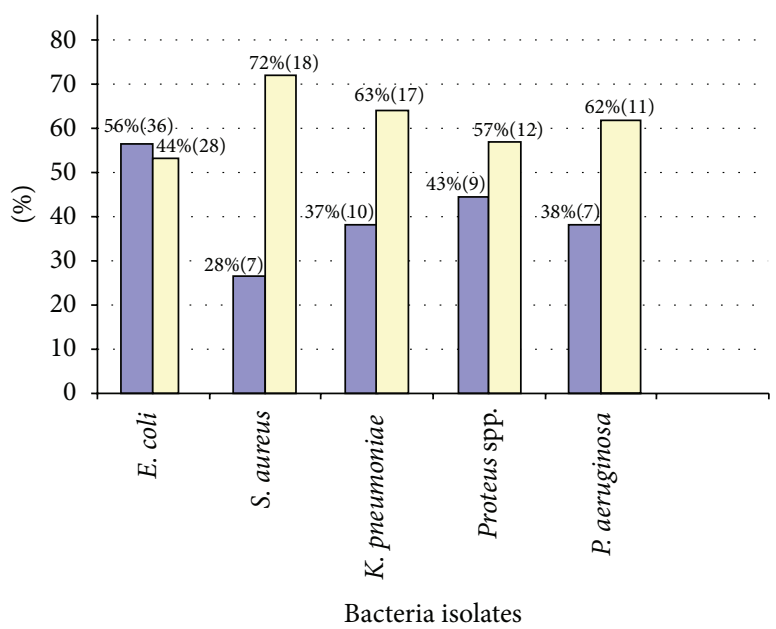

HIV POS

HIV NEG

FIgURE 2: Distribution of bacteria isolates in relation to HIV status. 
TABLE 2: Susceptibility data for common bacterial isolates to cotrimoxazole and other antimicrobials regardless of HIV or cotrimoxazole prophylaxis status.

\begin{tabular}{|c|c|c|c|c|c|c|}
\hline & $\begin{array}{c}\text { Resistant } \\
n \%\end{array}$ & $\begin{array}{c}\text { Susceptible } \\
n \% \\
\end{array}$ & $P$ & $\begin{array}{c}\text { Resistant } \\
n \%\end{array}$ & $\begin{array}{c}\text { Susceptible } \\
n \% \\
\end{array}$ & $P$ \\
\hline & \multicolumn{2}{|c|}{ Cotrimoxazole } & \multicolumn{4}{|c|}{ Amoxycillin-clavulanic } \\
\hline \multicolumn{7}{|l|}{ Bacteria isolates } \\
\hline E. coli & $54(84.4)$ & $10(15.6)$ & & $27(43.6)$ & $35(56.4)$ & \multirow{5}{*}{$<0.001$} \\
\hline S. aureus & $14(56.0)$ & $11(44.0)$ & & $3(13.0)$ & $20(87.0)$ & \\
\hline K. pneumoniae & $20(74.1)$ & $7(25.9)$ & 0.1 & $20(83.3)$ & $4(16.7)$ & \\
\hline P. aeruginosa & $7(87.5)$ & $1(12.5)$ & & $6(75.0)$ & $2(25.0)$ & \\
\hline \multirow[t]{2}{*}{ Proteus } & $17(80.9)$ & $4(19.1)$ & & $10(47.6)$ & $11(52.4)$ & \\
\hline & \multicolumn{2}{|c|}{ Erythromycin } & \multicolumn{4}{|c|}{ Ceftriaxone } \\
\hline \multicolumn{7}{|l|}{ Bacteria isolates } \\
\hline E. coli & $2(50.0)$ & $2(50.0)$ & & $16(48.5)$ & $17(51.5)$ & \multirow{5}{*}{0.08} \\
\hline S. aureus & $8(57.1)$ & $6(42.9)$ & & $4(30.8)$ & $9(69.2)$ & \\
\hline K. pneumoniae & $3(60.0)$ & $2(40.0)$ & & $13(72.2)$ & $5(27.9)$ & \\
\hline P. aeruginosa & $0(0.0)$ & $2(100.0)$ & & $1(25.0)$ & $3(75.0)$ & \\
\hline \multirow[t]{2}{*}{ Proteus } & - & - & & $4(33.3)$ & $8(66.7)$ & \\
\hline & \multicolumn{2}{|c|}{ Ciprofloxacin } & \multicolumn{4}{|c|}{ Ampicillin } \\
\hline \multicolumn{7}{|l|}{ Bacteria isolates } \\
\hline E. coli & $20(32.8)$ & $41(67.2)$ & \multirow{5}{*}{0.49} & $47(82.5)$ & $10(17.5)$ & \multirow{5}{*}{0.001} \\
\hline S. aureus & $3(13.6)$ & $19(86.4)$ & & $3(30.0)$ & $7(70.0)$ & \\
\hline K. pneumoniae & $6(26.1)$ & $17(73.9)$ & & $21(95.4)$ & $1(4.6)$ & \\
\hline P. aeruginosa & $1(16.7)$ & $5(83.3)$ & & $6(75.0)$ & $2(25.0)$ & \\
\hline \multirow[t]{2}{*}{ Proteus } & $5(25.0)$ & $15(75.0)$ & & $16(76.2)$ & $5(23.8)$ & \\
\hline & \multicolumn{2}{|c|}{ Tetracycline } & \multicolumn{4}{|c|}{ Cefuroxime } \\
\hline \multicolumn{7}{|l|}{ Bacteria isolates } \\
\hline E. coli & $29(78.4)$ & $8(21.6)$ & & $11(64.7)$ & $6(35.3)$ & \multirow{5}{*}{0.60} \\
\hline S. aureus & $4(44.4)$ & $5(55.6)$ & & $3(37.5)$ & $5(62.5)$ & \\
\hline K. pneumoniae & $19(95.0)$ & $1(5.0)$ & 0.03 & $10(71.4)$ & $4(28.6)$ & \\
\hline P. aeruginosa & $5(100.0)$ & $0(0.0)$ & & $2(66.7)$ & $1(33.3)$ & \\
\hline Proteus & $14(82.4)$ & $3(17.6)$ & & $5(45.5)$ & $6(54.5)$ & \\
\hline
\end{tabular}

bacterial isolates was significantly higher than that of nonESBL producing bacterial isolates $(P \leq 0.001)$ (Table 5$)$.

\section{Discussion}

The use of cotrimoxazole as an intervention to reduce the opportunistic infections in HIV positive patients is believed to highly reduce the morbidity and mortality in these patients [17]. UNAIDS recommends cotrimoxazole to be given to all HIV/AIDS patients in Africa [18], a practice which Tanzania has done for over 10 years now. However, selective pressure to bacteria due to constant exposure to antibiotic has been noted as the major contributor of antibacterial resistance developed by bacteria previously [2].

Despite the use of cotrimoxazole as prophylaxis in HIV positive patients, the current study detected that $46.4 \%$ of bacterial infection was from HIV positive patients. Of this $61 \%$ of bacteria were isolated from samples collected from HIV positive patients on prophylaxis. This might be either due to antibiotic resistance of these bacteria to cotrimoxazole or due to the WHO HIV stage, at which the use of prophylaxis agent is initiated in Tanzania.

Like it has been pointed out in other studies undertaken in Bugando Medical Centre [19-21] this study detected E. coli and Klebsiella species as the most common bacteria among gram negative bacteria and $S$. aureus as the commonest gram positive bacteria. In this study, E. coli resistance to cotrimoxazole among HIV positive patients suggests that HIV positive patients do not significantly harbor bacterial isolates with higher resistance to antimicrobials compared to HIV negative patients as seen from studies done elsewhere [22-24]. Similar findings were observed with Klebsiella pneumoniae, whereby there was no significant difference in bacterial resistance between HIV/AIDS patients and non-HIV patients to cotrimoxazole, amoxycillin-clavulanic acid, and ciprofloxacin, findings which are comparable with findings from other studies $[23,24]$. Furthermore, the same results were observed with Staphylococcus aureus and Proteus species.

In our study we found a very high resistance to amoxicillin-clavulanic acid among ESBL producers (100\%); this is comparable to a study done at the ICU Department 
TABLE 3: Antimicrobial resistance patterns based on HIV status.

\begin{tabular}{|c|c|c|c|c|}
\hline \multirow{3}{*}{ Antimicrobial agent } & \multicolumn{2}{|c|}{ HIV status } & \multirow{3}{*}{$P$} & \multirow{3}{*}{$\begin{array}{c}\text { Crude } \\
\text { OR (95\% CI) }\end{array}$} \\
\hline & Negative & Positive & & \\
\hline & $N(\%)$ & $N(\%)$ & & \\
\hline \multicolumn{5}{|l|}{ Cotrimoxazole } \\
\hline Resistant & $64(77.1)$ & $54(75)$ & \multirow{2}{*}{0.76} & 1 \\
\hline Susceptible & $19(22.9)$ & $18(25)$ & & $0.89(0.42-1.87)$ \\
\hline \multicolumn{5}{|c|}{ Amoxycillin-clavulanic acid } \\
\hline Resistant & $47(60.0)$ & $23(34.0)$ & \multirow{2}{*}{0.02} & 1 \\
\hline Susceptible & $32(40.0)$ & $45(66.0)$ & & $0.35(0.17-0.70)$ \\
\hline \multicolumn{5}{|l|}{ Ciprofloxacin } \\
\hline Resistant & $14(19.0)$ & $22(33.3)$ & \multirow{2}{*}{0.07} & 1 \\
\hline Susceptible & $58(81.0)$ & $44(66.7)$ & & $2.07(0.94-4.56)$ \\
\hline \multicolumn{5}{|l|}{ Ampicillin } \\
\hline Resistant & $49(72.1)$ & $51(86.4)$ & \multirow{2}{*}{0.06} & 1 \\
\hline Susceptible & $19(27.9)$ & $8(13.6)$ & & $2.47(0.97-6.28)$ \\
\hline \multicolumn{5}{|l|}{ Ceftriaxone } \\
\hline Resistant & $21(42.9)$ & $6(66.7)$ & \multirow{2}{*}{0.59} & 1 \\
\hline Susceptible & $28(57.1)$ & $3(33.3)$ & & $1.50(0.33-6.81)$ \\
\hline \multicolumn{5}{|l|}{ Tetracycline } \\
\hline Resistant & $51(82.3)$ & $26(81.3)$ & \multirow{2}{*}{0.91} & 1 \\
\hline Susceptible & $11(17.7)$ & $6(18.7)$ & & $0.94(0.31-2.83)$ \\
\hline \multicolumn{5}{|l|}{ Erythromycin } \\
\hline Resistant & $11(64.7)$ & $3(27.3)$ & \multirow{2}{*}{0.06} & 1 \\
\hline Susceptible & $6(35.3)$ & $8(72.7)$ & & $0.21(0.03-1.26)$ \\
\hline
\end{tabular}

TABLE 4: Susceptibility data for isolates among HIV patients on prophylaxis and those not on prophylaxis.

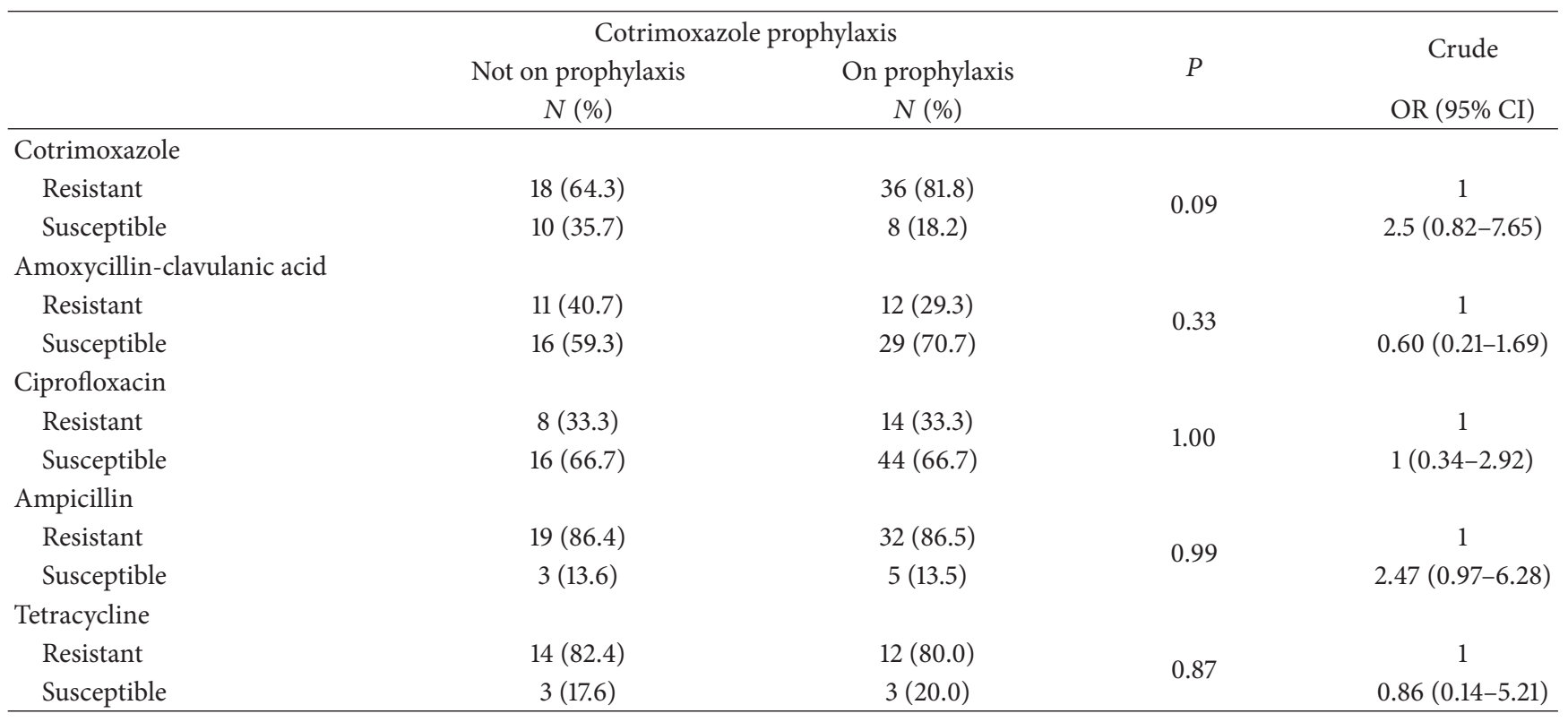

of Muhimbili National Hospital of Tanzania [25] and is threatening, as it suggests that there might be an increase of ESBL producing bacteria in our community.

Hospitalization has been shown as a risk factor for acquisition of ESBL producing bacteria [26, 27]. In the current study, HIV negative patients are infected with more resistant E. coli isolates (67.9\%) than HIV/AIDS patients (23.6\%). This finding may be due to the fact that most HIV negative patients (75.5\%) in our study were inpatients/hospitalized compared to HIV positive patients who were outpatients from Care 
TABLE 5: Predictors of ESBL producing isolates among 155 clinical isolates.

\begin{tabular}{|c|c|c|c|c|}
\hline & $\begin{array}{c}\text { ESBL nonproducer } \\
n \%\end{array}$ & $\begin{array}{c}\text { ESBL producer } \\
n \%\end{array}$ & $P$ & $\begin{array}{c}\text { Crude } \\
\text { OR }(95 \% \text { CI })\end{array}$ \\
\hline \multicolumn{5}{|l|}{ Cotrimoxazole } \\
\hline Resistant & $83(69.8)$ & $35(97.2)$ & \multirow{2}{*}{0.001} & 1 \\
\hline Susceptible & $36(30.2)$ & $1(2.8)$ & & $15(1.85-125.5)$ \\
\hline \multicolumn{5}{|c|}{ Amoxycillin-clavulanic } \\
\hline Resistant & $35(31.3)$ & $35(100)$ & \multirow{2}{*}{$<0.001$} & \multirow{2}{*}{ NA } \\
\hline Susceptible & $77(68.7)$ & $0 .(0.0)$ & & \\
\hline \multicolumn{5}{|l|}{ Ciprofloxacin } \\
\hline Resistant & $14(12.9)$ & $22(75.9)$ & \multirow{2}{*}{$<0.001$} & 1 \\
\hline Susceptible & $95(87.1)$ & $7(24.1)$ & & $0.05(0.01-0.13)$ \\
\hline \multicolumn{5}{|l|}{ Ampicillin } \\
\hline Resistant & $71(72.5)$ & $29(100)$ & \multirow{2}{*}{0.001} & \multirow{2}{*}{ NA } \\
\hline Susceptible & $27(27.5)$ & $0(0.0)$ & & \\
\hline \multicolumn{5}{|l|}{ Tetracycline } \\
\hline Resistant & $47(73.4)$ & $30(100)$ & \multirow{2}{*}{0.002} & \multirow{2}{*}{ NA } \\
\hline Susceptible & $17(26.6)$ & $0(0.0)$ & & \\
\hline \multicolumn{5}{|l|}{ Ceftriaxone } \\
\hline Resistant & $19(47.5)$ & $15(83.3)$ & \multirow{2}{*}{0.01} & 1 \\
\hline Susceptible & $21(52.5)$ & $3(16.7)$ & & $5.52(1.26-24.4)$ \\
\hline \multicolumn{5}{|l|}{ HIV status } \\
\hline Negative & $64(53.8)$ & $19(52.8)$ & \multirow{2}{*}{0.92} & 1 \\
\hline Positive & $55(46.2)$ & $17(47.2)$ & & $1.04(0.49-2.19)$ \\
\hline \multicolumn{5}{|c|}{ Cotrimoxazole prophylaxis } \\
\hline No & 23 (41.9) & $5(29.4)$ & \multirow{2}{*}{0.36} & 1 \\
\hline Yes & $32(58.1)$ & $12(70.6)$ & & $1.72(0.53-5.57)$ \\
\hline
\end{tabular}

and Treatment Center (CTC). Surprisingly, these results were not observed with S. aureus, K. pneumoniae, and Proteus mirabilis.

In this study, there was no significant difference in bacterial resistance to cotrimoxazole, ampicillin, tetracycline, and ciprofloxacin, between isolates from HIV/AIDS patients on cotrimoxazole prophylaxis, compared to those not on prophylaxis. This is similar to previous reports [28-30]. These findings can either suggest that majority of the bacterial pathogens have acquired resistance to cotrimoxazole due to selective pressure after more than ten years of this prophylactic practice, or cotrimoxazole prophylaxis is not a determining factor, since bacteria were resistant to cotrimoxazole long time ago [31].

Studies had established at the time of introducing cotrimoxazole prophylaxis more than ten years ago that cotrimoxazole prophylaxis reduces morbidity and mortality among HIV positive patients. The present situation may be different, as more than $80 \%$ of the bacteria causing opportunistic infections are resistant to cotrimoxazole.

Pneumocystis jiroveci which is the main target in cotrimoxazole prophylaxis among HIV/AIDS patients was not cultured in our laboratory. In this study, cross resistance between cotrimoxazole and other antimicrobials was not assessed. These may be limitations to the findings in our study.

Recommendation. Further studies are needed to assess the current morbidity and mortality in HIV positive patients taking prophylactic cotrimoxazole, in view of the findings that bacterial resistance to cotrimoxazole is high. Since the use of cotrimoxazole for prophylaxis in HIV positive patients is on-going as a policy of the government of Tanzania and many other countries, further studies are warranted with bigger participant populations to determine the prevalence of resistance to cotrimoxazole (and other antimicrobials) in these patients.

\section{Conflict of Interests}

The authors declare that they have no competing interests.

\section{Acknowledgments}

This work was supported by the Catholic University of Health and Allied Sciences. The authors are grateful for the support provided by the BMC and CUHAS Clinical Laboratory staff in making this work possible. 


\section{References}

[1] I. N. Okeke, R. Laxminarayan, Z. A. Bhutta et al., "Antimicrobial resistance in developing countries. Part I: recent trends and current status," The Lancet Infectious Diseases, vol. 5, no. 8, pp. 481-493, 2005.

[2] M. F. Mushi, S. E. Mshana, C. Imirzalioglu, and F. Bwanga, "Carbapenemase genes among multidrug resistant gram negative clinical isolates from a tertiary hospital in Mwanza, Tanzania," BioMed Research International, vol. 2014, Article ID 303104, 6 pages, 2014.

[3] R. D. Smith and J. Coast, "Antimicrobial resistance: a global response," Bulletin of the World Health Organization, vol. 80, no. 2, pp. 126-133, 2002.

[4] Resistance USITFoA, 2009-2010 Progress Towards Implementation of: A Public Health Action Plan to Combat Antimicrobial Resistance, Interagency Task Force on Antimicrobial Resistance, 2011.

[5] K. A. Johansson, D. Jerene, and O. F. Norheim, "National HIV treatment guidelines in Tanzania and Ethiopia: are they legitimate rationing tools?" Journal of Medical Ethics, vol. 34, no. 6, pp. 478-483, 2008.

[6] J. Vila, M. Vargas, C. Casals et al., "Antimicrobial resistance of diarrheagenic Escherichia coli isolated from children under the age of 5 years from Ifakara, Tanzania," Antimicrobial Agents and Chemotherapy, vol. 43, no. 12, pp. 3022-3024, 1999.

[7] F. C. Tenover, "Mechanisms of antimicrobial resistance in bacteria," The American Journal of Medicine, vol. 119, supplement 1, no. 6, pp. S3-S70, 2006.

[8] H. Maortua, A. Canut, B. Ibáñez, D. Martínez, M. J. De Domingo, and A. Labora, "Relationship between in-hospital bacterial resistance and antimicrobial use over a 13-year period," Enfermedades Infecciosas y Microbiologia Clinica, vol. 27, no. 8, pp. 441-448, 2009.

[9] A.-M. Rogues, C. Dumartin, B. Amadéo et al., "Relationship between rates of antimicrobial consumption and the incidence of antimicrobial resistance in Staphylococcus aureus and Pseudomonas aeruginosa isolates from 47 French hospitals," Infection Control and Hospital Epidemiology, vol. 28, no. 12, pp.1389-1395, 2007.

[10] E. Iosifidis, C. Antachopoulos, M. Tsivitanidou et al., "Differential correlation between rates of antimicrobial drug consumption and prevalence of antimicrobial resistance in a tertiary care hospital in Greece," Infection Control and Hospital Epidemiology, vol. 29, no. 7, pp. 615-622, 2008.

[11] S. A. Madhi, K. Petersen, A. Madhi, M. Khoosal, and K. P. Klugman, "Increased disease burden and antibiotic resistance of bacteria causing severe community-acquired lower respiratory tract infections in human immunodeficiency virus type 1infected children," Clinical Infectious Diseases, vol. 31, no. 1, pp. 170-176, 2000.

[12] M. Cheesborough, "Microbiology", in District Laboratory Practice in Tropical Countries Vol. II, pp. 158-195, Cambridge University Press, 2nd edition, 2006.

[13] M. A. Wikler, Performance Standards for Antimicrobial Susceptibility Testing: Twentieth Informational Supplement, Clinical and Laboratory Standards Institute, 2010.

[14] M. J. Perilla, G. Ajello, C. Bopp et al., Manual for the Laboratory Identification and Antimicrobial Susceptibility Testing of Bacterial Pathogens of Public Health Importance in the Developing World: Haemophilus influenzae, Neisseria meningitidis, Streptococcus pneumoniae, Neisseria gonorrhoeae, Salmonella serotype
Typhi, Shigella, and Vibrio cholerae, Centers for Disease Control and Prevention, National Center for Infectious Diseases, 2003.

[15] S. E. Mshana, E. Kamugisha, M. Mirambo, T. Chakraborty, and E. F. Lyamuya, "Prevalence of multi-resistant gram-negative organisms in a tertiary hospital in Mwanza, Tanzania," BMC Research Notes, vol. 2, article 49, 2009.

[16] Jamii TWyAnUw, Programme NAC: National Guidelines for the Management of HIV and AIDS, National Aids Control Programme, 2008.

[17] R. Zachariah, M. P. Spielmann, A. D. Harries, P. Gomani, and E. Bakali, "Cotrimoxazole prophylaxis in HIV-infected individuals after completing anti-tuberculosis treatment in Thyolo, Malawi," International Journal of Tuberculosis and Lung Disease, vol. 6, no. 12, pp. 1046-1050, 2002.

[18] WHO, Provisional WHO/UNAIDS Secretariat Recommendations on the Use of Cotrimoxazole Prophylaxis in Adults and Children Living with HIV/AIDS in Africa, WHO, Geneva, Switzerland, 2000.

[19] E. Nelson, J. Kayega, J. Seni et al., "Evaluation of existence and transmission of extended spectrum beta lactamase producing bacteria from post-delivery women to neonates at Bugando Medical Center, Mwanza-Tanzania," BMC Research Notes, vol. 7, no. 1, article 279, 2014.

[20] N. Kayange, E. Kamugisha, D. L. Mwizamholya, S. Jeremiah, and S. E. Mshana, "Predictors of positive blood culture and deaths among neonates with suspected neonatal sepsis in a tertiary hospital, Mwanza-Tanzania," BMC Pediatrics, vol. 10, no. 1, article 39, 2010.

[21] N. Moremi, M. F. Mushi, M. Fidelis, P. Chalya, M. Mirambo, and S. E. Mshana, "Predominance of multi-resistant gramnegative bacteria colonizing chronic lower limb ulcers (CLLUs) at Bugando Medical Center," BMC Research Notes, vol. 7, no. 1, article 211, 2014.

[22] S. C. Morpeth, N. M. Thielman, H. O. Ramadhani et al., "Effect of trimethoprim-sulfamethoxazole prophylaxis on antimicrobial resistance of fecal Escherichia coli in HIV-infected patients in Tanzania," Journal of Acquired Immune Deficiency Syndromes, vol. 47, no. 5, pp. 585-591, 2008.

[23] A. S. Karstaedt, M. Khoosal, and H. H. Crewe-Brown, "Pneumococcal bacteremia during a decade in children in Soweto, South Africa," Pediatric Infectious Disease Journal, vol. 19, no. 5, pp. 454-457, 2000.

[24] E. Leibovitz, C. Dragomir, S. Sfartz et al., "Nasopharyngeal carriage of multidrug-resistant Streptococcus pneumoniae in institutionalized HIV-infected and HIV-negative children in northeastern Romania," International Journal of Infectious Diseases, vol. 3, no. 4, pp. 211-215, 1999.

[25] F. Ndugulile, R. Jureen, S. Harthug, W. Urassa, and N. Langeland, "Extended spectrum $\beta$-lactamases among Gram-negative bacteria of nosocomial origin from an Intensive Care Unit of a tertiary health facility in Tanzania," BMC Infectious Diseases, vol. 5, article 86, 2005.

[26] I. Skippen, M. Shemko, J. Turton, M. E. Kaufmann, C. Palmer, and N. Shetty, "Epidemiology of infections caused by extendedspectrum $\beta$-lactamase-producing Escherichia coli and Klebsiella spp.: a nested case-control study from a tertiary hospital in London," Journal of Hospital Infection, vol. 64, no. 2, pp. 115-123, 2006.

[27] S. Shakil, M. Akram, S. M. Ali, and A. U. Khan, "Acquisition of extended-spectrum $\beta$-lactamase producing Escherichia coli strains in male and female infants admitted to a neonatal intensive care unit: molecular epidemiology and analysis of risk 
factors," Journal of Medical Microbiology, vol. 59, part 8, pp. 948954, 2010.

[28] J. Mermin, J. Lule, J. P. Ekwaru et al., "Cotrimoxazole prophylaxis by HIV-infected persons in Uganda reduces morbidity and mortality among HIV-uninfected family members," AIDS, vol. 19, no. 10, pp. 1035-1042, 2005.

[29] M. F. Cotton, E. Wasserman, J. Smit, A. Whitelaw, and H. J. Zar, "High incidence of antimicrobial resistant organisms including extended spectrum beta-lactamase producing Enterobacteriaceae and methicillin-resistant Staphylococcus aureus in nasopharyngeal and blood isolates of HIV-infected children from Cape Town, South Africa," BMC Infectious Diseases, vol. 8, article 40, 2008.

[30] X. Anglaret, G. Chêne, A. Attia et al., "Early chemoprophylaxis with trimethoprim-sulphamethoxazole for HIV-1-infected adults in Abidjan, Cote d'Ivoire: a randomised trial,' The Lancet, vol. 353, no. 9163, pp. 1463-1468, 1999.

[31] S. C. Morpeth, N. M. Thielman, H. O. Ramadhani et al., "Effect of trimethoprim-sulfamethoxazole prophylaxis on antimicrobial resistance of fecal Escherichia coli in HIV-infected patients in Tanzania," Journal of Acquired Immune Deficiency Syndromes, vol. 47, no. 5, pp. 585-591, 2008. 


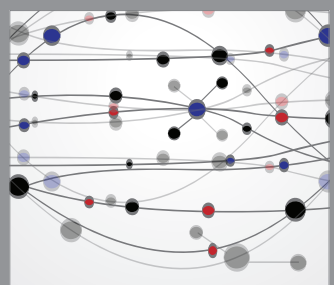

The Scientific World Journal
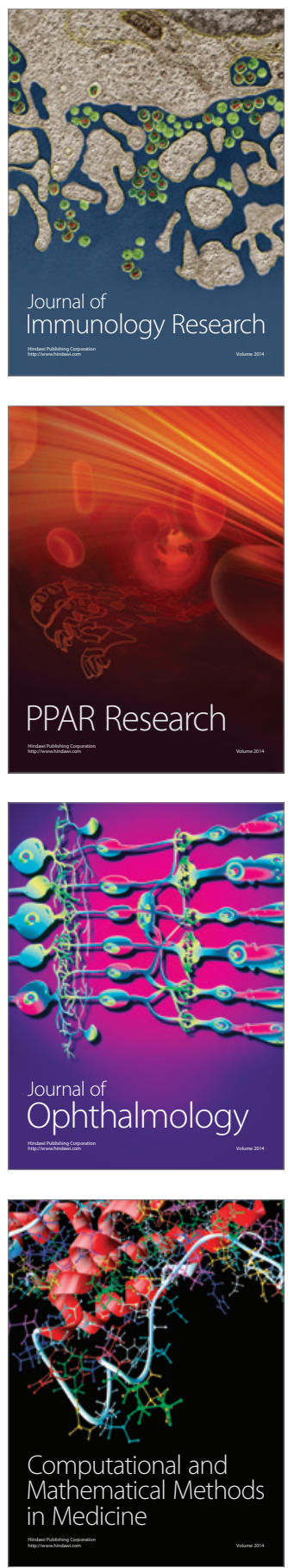

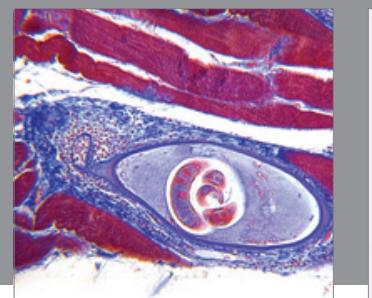

Gastroenterology

Research and Practice
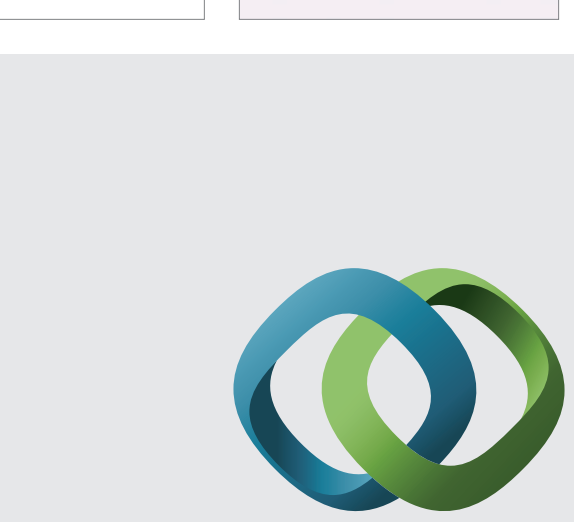

\section{Hindawi}

Submit your manuscripts at

http://www.hindawi.com
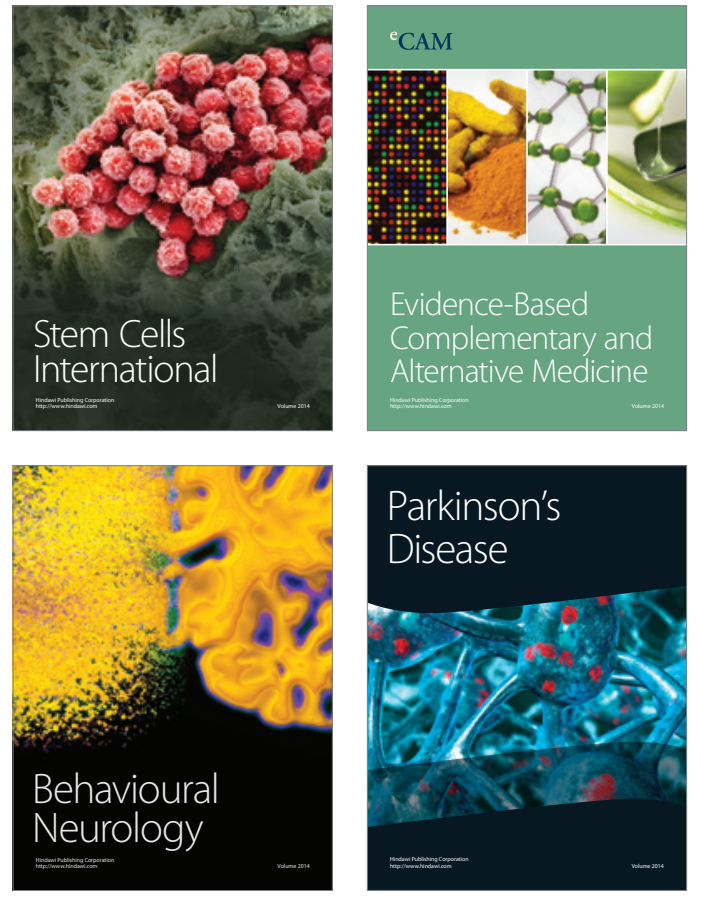
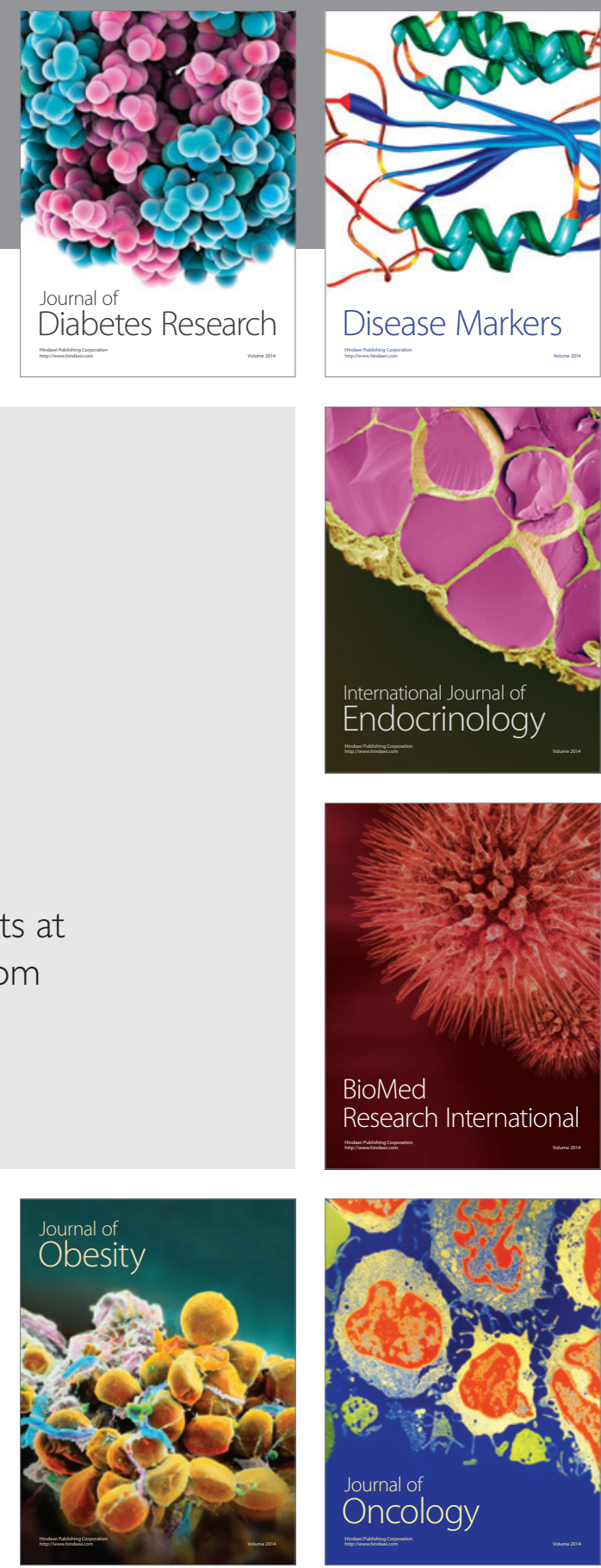

Disease Markers
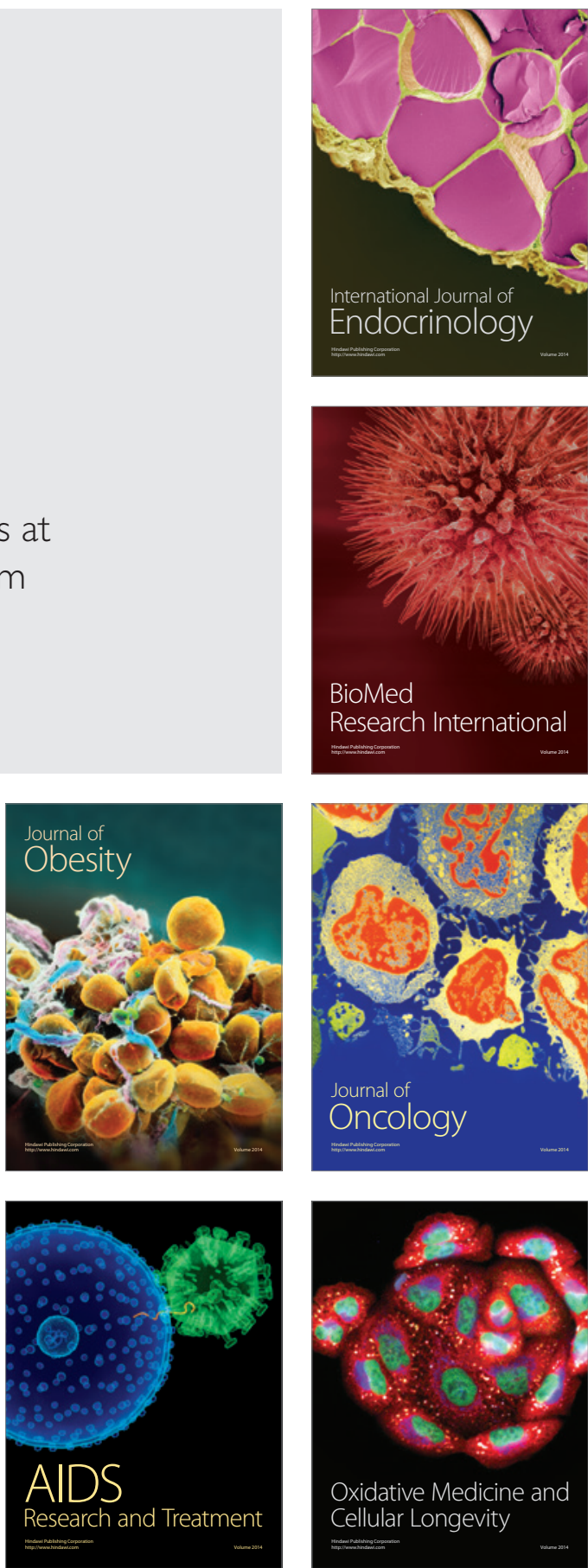